Our love was a two-person game. At least until one of us died, and the other became a murderer: Sexual homicide perpetrated by intimate partners. 


\begin{abstract}
Little is known about crime event characteristics of sexual homicides perpetrated by intimate partners. The current study aimed to address this void by examining crime scene and Modus Operandi behaviours of intimate partners who killed their victims in a sexual context. The sample comprised of 71 males serving a custodial sentence for murder or manslaughter who were assessed as sexual homicide perpetrators. Intimate partners included current or former partners, irrespective of marital status. The study was exploratory in nature and the variables were chosen based on previous research examining both sexual homicides and intimate partner homicides. Descriptive analyses indicated that the most prevalent aggravating circumstances in the lead up to the killing included conflict with the victim before the offence and substance use by the perpetrator around the time of the killing. Stalking was present in approximately a quarter of cases. The results of the analyses of sexual behaviours showed that in $54.9 \%$ of the sample the act of killing was purely instrumental whereas in $39.4 \%$ of the sample the underlying drive of the act of killing was closely related to the sexual aspect. Keywords: Intimate partner, violence, homicide, sexual killing.
\end{abstract}




\section{Our love was a two-person game. At least until one of us died, and the other became a murderer: Sexual homicide perpetrated by intimate partners.}

Intimacy is the feeling of being close to another human either physically, sexually and/or emotionally. Intimate partner relationship describes a relationship between two people characterised by some form of intimacy. Such relationships are part of the core of the human experience (Pettler, 2015).

\section{Intimate partner violence and lethal acts}

Intimate partner violence (IPV) is a global concern that can occur across all socioeconomic and cultural groups. The behaviour occurs regardless of gender or sexuality and it may encompass various forms, including physical and/or sexual violence as well as other forms of abuse such as psychological or financial. In addition, controlling behaviours include acts designed to make a person subordinate and/or dependent by isolating them from sources of support, exploiting their resources and capacities for personal gain, depriving them of the means needed for independence, resistance and escape and regulating their everyday behaviour (WHO, 2017; Home Office, 2013).

Studies of lethal and nonlethal violence indicate that IPV exhibits unique epidemiology and thus, should be regarded separately from general violence (Frye et al., 2005). However, whether or not IPV and Intimate Partner Homicide (IPH) offenders differ is more equivocal. Some scholars regard intimate violence as occurring on a continuum with IPH being the most extreme form of IPV (Reckdenwald \& Parker, 2012), a similar argument to that of sexual homicide. All types of IPV perpetration have the potential to escalate in type and severity that can lead to severe forms of violence ending in the death of the victim, whether planned or unplanned. Having said that, as with sexual homicide being on a continuum of sexual violence, other scholars note that most IPV incidents do not end in IPH. While IPH rarely 
occurs as an isolated incident, research argues that IPH cannot be predicted on nonlethal partner violence (Goussinsky \& Yassour-Borochowitz, 2012; Marias el a., 2020).

\section{Intimate partner homicide}

In line with other IPV perpetrators, intimate partner killers can be of any origin, social class, or level of education (Aldarondo \& Mederos, 2002). Although both men and women can be victimised, females are more likely to be the victims of such killings (Cooper et al.,, 2011; McFarlane et al., 2002; Rennison \& Welchans, 2000). All types of union i.e. married, common-law or couples not living together are equally at risk (Cunha \& Goncalves, 2016). The factors that may put the individual in a relationship at a greater risk of IPH have recently been consolidated by two independent meta-analyses where fatal and non-fatal abusive relationships were examined. In terms of perpetrator characteristics, Matias et al (2020) found that IPH perpetrators were more likely to have a lower education level, prior criminal records, history of violence in previous relationships, exhibit suicidal thoughts or have suicide attempts. Lower education level, offender's history of mental health problems and prior relationship abuse (as noted by controlling behaviours and abuse of the victim while pregnant, threatening harm) were also noted by Spencer \& Stith (2020). However, in contrast to Matias et al (2020), Spencer and Stith (2020) did not find that having prior criminal charges was a significant predictor.

With regards to the elements of the situational context of intimate partner homicide, research suggests that access to weapons increases the likelihood of an attack being lethal. Specifically, access to guns was predictive (e.g. Campbell et al; 2003; Campbell et al., 2007; Fox \& Zawitz, 2004) and both meta-analyses confirmed that if the perpetrator had direct access to guns, the likelihood of IPH increased by 11 times (Matias et al., 2020; Spencer \& Stith, 2020). These statistics however mainly corroborate information gathered from studies examining homicide in the USA, which might not be representative of situations in other 
countries where access to firearms is restricted. The Home Office statistics from the UK for instance indicate that most domestic female victims died from wounds inflicted by a sharp instrument (Office for National Statistics, 2019). This is in line with findings from Finland, the Netherlands and Sweden where the majority of cases were also committed by a knife or a sharp weapon (Liem \& Koenraadt, 2018). Research additionally indicates that substance use was correlated with higher incidence rates of intimate partner homicide. Spencer and Stith (2020) found that if the perpetrator abused alcohol and drugs, the likelihood of IPH increased by almost two times whereas IPH against female victims specifically by just over two times. Additionally, the likelihood of IPH against female victims increased by approximately two times when the victim abused substances. Similar results were obtained by Matias et al (2020) when looking separately at alcohol and drug use in both perpetrators and victims. Location has not been addressed by meta-analyses, but research suggests that home is a common location as it provides privacy (Miethe \& Regoeczi, 2016) and allows for more physical opportunities with higher frequency of social interactions between the victim and the perpetrator (Pettler, 2015). However, apart from the few aforementioned situational components, little research exists focusing on situational and Modus Operandi (MO) factors in more detail among intimate homicides.

\section{Motivation}

Intimate partner killings can be motivated by a wide array of factors. Some can be goal directed, others appear to be more spontaneous and impulsive (Miethe \& Regoeczi, 2004). In general however, jealousy and desire to control are the primary drivers behind male perpetrator intimate killings (Matias et al, 2020; Spencer \& Stith, 2020). Female victims are more at risk in the context of pending estrangement, when they are trying to leave or have recently ended the relationship, increasing the likelihood of IPH of female victims by over two times (Spencer \& Stith, 2020). Interestingly, meta-analyses also suggested that previous 
use of non-fatal strangulation, homicide ideation and threats as well as stalking significantly increase the chances of assaults leading to homicide (Matias et al, 2020; Spencer \& Stith, 2020) indicating that perhaps lethal acts might not have been as spontaneous as they appeared (Stefanska et al., 2020). Interestingly, Spencer and Stith (2020) also noted that the risk of homicide increased if the perpetrator forced sex on the victim. In fact, forced sex increased the likelihood of IPH by over five times. When sexual violence was used, other risky behaviours, such as non-fatal strangulation, were also more likely to be used at the same time.

\section{Sexual homicide}

To understand what differentiates non-lethal from lethal sexual assaults, research compared sexual killers with sexual aggressors (specifically perpetrators of rape or attempted rape). Overall, the results indicated that the groups appeared to have many similarities in terms of general upbringing, personal victimisation, family structure or previous criminal history (e.g. Beech et al., 2005; Langevin et al., 1988; Nicole \& Proulx, 2007). Some distinguishing characteristics were also noted. For example, sexual killers were more likely to be diagnosed with sadism (Langevin et a., 1988; Proulx \& Sauvêtre, 2007), tended to be emotionally lonely (Grubin, 1994; Milsom et al., 2003) and be socially isolated in adolescence (Nicole \& Proulx, 2007). Elements of the situational context of sexual homicide indicate that the assault is more likely to be lethal if the perpetrator carries a weapon, even if it is carried for control purposes (Chéné \& Cusson, 2007). However, unlike in intimate partner homicide offenders, sexual killers tend to use close-contact killing methods, such as murder by strangulation, beating, or asphyxiation (Chan \& Beauregard, 2016; Chan et al., 2019; Greenall \& Richardson, 2015; Proulx et al., 2013). Similar to intimate partner homicide perpetrators, presence of alcohol at the time of the crime was shown to increase both the likelihood of victim physical injury and victim death (Mieczkowski \& Beauregard, 2012). An 
important limitation to these studies lies in the fact that when comparing lethal with nonlethal sexual assaults, very violent sex offenders and non-violent sex offenders were merged. Indeed, when 1) non-violent and 2) violent non-lethal assaults were compared with 3) sexual homicides, differences emerged in developmental factors (Beauregard \& DeLisi, 2018a) as well as in regards to personality profiles for these perpetrators (Beauregard \& DeLisi, 2018b).

\section{Motivation}

While killing in pursuit of sadistic sexual gratification is often noted in sexual homicide, it is not a feature of all cases. Classification studies additionally identified angry sexual murderers who kill due to rage experience before or during the attack (Beauregard \& Proulx, 2002; Beauregard et al., 2007; Kocsis, 1999) as well as sexually motivated murderers whose main objective was sexual assault (Beech et al., 2005; Clarke \& Carter, 2000; Kocsis, 1999). However, Stefanska et al., (2020) argued that from a clinical standpoint, taking into account motivation as a primary feature for understanding sexual killings has limited utility. This is because the killings occur in a variety of different situational contexts (Beauregard \& Martineau, 2016; Stefanska et al., 2017). Given that sexual homicide is a hybrid offence which combines a sexual assault and an act of homicide (Carter \& Hollin, 2014), Stefanska et al., (2020) postulated that it is more advantageous to consider the different ways the sexual behaviour and the killing are related within the criminal event as this will help to understand the sexual nature of homicide. Interestingly, Chan et al (2019) noted that perpetrators who were primarily motivated by power and control were more likely to target an intimate partner.

\section{Current study}

Spencer \& Stith (2020) argue that significant risk factors for IPH are in line with the sexual proprietariness theory. If the perpetrator displays controlling behaviours towards to the victim, is sexually jealous especially when the victim has or is considering separation, the perpetrator is stalking the victim and has perpetrated forced sex, the potential for 
dangerousness of the situation increases, and as such these indicators should be treated as warning signs. The timeline of sexual violence however has not been addressed, and the authors do not specify whether sexual violence took place before the homicide incident or around the time of the incident. This is important because if sexual violence took place around the time of IPH, due to forensic evidence, such a case would be considered a sexual homicide regardless of who was the perpetrator. Currently, definitional criteria of sexual homicide are based on crime scene indicators that a sexual element took place and little consideration is given as to the relationship between the perpetrator and the victim. It could be argued that this is appropriate operationalisation, because sexual homicide represents a hybrid offence combining two different offences, a sexual assault and a homicide and understanding that hybrid should be the primary focus of psychological investigation (Stefanska et al, 2020). Nevertheless, due to the sexual nature of the relationship between the victim and the perpetrator, further understanding of intimate partner sexual homicide dyads is crucial. However, to our knowledge, there are no studies investigating sexual homicide perpetrated by intimate partners, therefore the current study aims to address that void. While the study sets out to examine various components of the crime event, the study represents an initial attempt to examine sexual homicide perpetrated by intimate partners and as such it is exploratory in nature.

\section{Method}

\section{Sample}

The sample used in the study consisted of male sexual killers, who perpetrated against pubescent female victims (14 years old and over) and served a custodial sentence within HM Prison Service in England and Wales. Sexual homicides were defined as offences where a sexual element in the killing was evidenced, suspected or admitted. Intimate partner 
homicides included current or former intimate partner, irrespective of marital status, where both partners were romantically involved. Relationships comprising of temporary sexual acquaintances, such as one-night stands, were not considered intimate partners. The sample represented a full data search of all cases stored in the Offender Assessment System in England and Wales. It captured cases stored from the beginning of its existence in the early 2000's. This means that from that date (early 2000's), the offender was still serving a prison sentence but the actual time frame of the index offences committed by the perpetrators ranged from the 1950 's to 2010 's. Out of the sample of offenders assessed by the prison service as those who committed a sexual homicide, 71 were perpetrated by an intimate partner and these comprised the final sample. Further details regarding criminal events were collected from the electronic and/or physical files from the Public Protection Unit Database (PPUD) of the Home Office which are collected for Parole Board purposes.

\section{Procedure and analytical strategy}

The analyses related to crime event characteristics and perpetrator's $M O$ were descriptive. All variables were coded as either absent or present $(0=$ no, $1=$ yes $)$ for each offender in the sample. Research examining intimate partner homicide and sexual homicide steered our choice of the variables included in the present study.

\section{Aggravating circumstances}

Variables related to early crime phase and situational context known to increase the likelihood of a lethal act in intimate partner violence were coded here. These included: (1) conflict with victim before the offence (approximately 48 hours before until immediately before the killing); (2) intoxication (cases were excluded if alcohol level was deemed not apparently relevant i.e. low levels such as one pint); (3) stalking or harassment (this needed to be clearly noted in the official files, targeting the victim immediately prior to the offence and/or following her before the attack was excluded as this does not constitute stalking). 


\section{Other crime characteristics}

Variables included: (1) place of killing being the home (regardless if it belonged to the victim, perpetrator or shared); (2) exertion of power, control, dominance ${ }^{1}$; (3) degrading, humiliating behaviour ${ }^{2}$.

\section{Violent behaviours}

Violent behaviour used during the crime event. These included: (1) killing by stabbing; (2) killing by beating; (3) killing by strangulation; (4) expressive physical violence $^{3}$; (5) mutilation (of sexual or other body parts that occurred either pre- or most mortem).

\section{Sexual behaviours}

Sexual behaviour exhibited during the crime event. These included: (1) vaginal penetration; (2) anal penetration; (3) post mortem sexual acts (as stated in the pathology report).

\section{Post-offence behaviours}

Behaviour evident at the post offence phase. These included: (1) body left as is; (2) turned himself into police; (3) carried on with routine activities.

To further appropriately consider the nature of the sexual element within the criminal event and the link between the sexual behaviours and the act of killing in intimate partner homicide, the study used a new classification of sexual motivated homicides proposed by Stefanska et al. (2017) and Stefanska et al. (2020). The assignment process for cases

\footnotetext{
${ }^{1}$ Item 2 of the Severe Sexual Sadism Scale; SeSaS - the item was deemed as present if the subject demonstrated his control and superiority during the offence as a purpose unto itself. During the offence, the subject may have spent considerable time on such demonstrations of power. The demonstrations of power were higher than would have been necessary to carry out the violent offence as such

${ }^{2}$ Item 4 of the $\mathrm{SeSaS}$ - regarded as present if the subject acted out behaviours that aimed to cause feelings of shame or disgust in the victim

${ }^{3}$ Item 7 of the SeSaS - regarded as present when the level of violence exerted was clearly out of proportion and exceeded the level that would be necessary to control the victim
} 
belonging to either direct or indirect groups closely followed the procedure described in Stefanska et al. (2017) and Stefanska et al. (2020). The direct profile consisted of cases where sufficient evidence suggested that the act of killing was a source of sexual stimulation for the perpetrator or when the killing enabled the perpetrator to carry out sexual acts with the victim's body. The indirect profile consisted of cases where killing did not have any sexual function but was purely instrumental. It was carried out to eliminate the witness, the victim was killed while defending herself or were violence was not sexually driven but the homicide occurred in a sexual context. Two raters blind-coded $10 \%$ of the same cases in order to establish inter-rater reliability of the framework. The strength of agreement using Fleiss (1981) criteria was excellent (Cohen's Kappa $=0.91)$.

\section{Results}

The results from the descriptive analysis related to crime event characteristics presented in Table 1 show that conflict with the victim before the offence was prevalent (60.6\% of cases) and many perpetrators (47.9\%) were intoxicated during the commissioning of the crime. Evidence of stalking or harassment prior to killing was noted among $18.3 \%$ of cases. During the criminal event, many perpetrators demonstrated their power, control and superiority (62\%). Although present, degrading and humiliating behaviour was less common (22.5\%). Most frequent method of killing was strangulation (54.9\%) whereas stabbing and beating was found among $16.9 \%$ of cases. Not surprisingly, the majority of homicides took place at home (78.9\%). Expressive physical violence that exceeded the level that would be necessary to control the victim was found in $33.8 \%$ of killings and some perpetrators mutilated their victims either pre or post-mortem (16.9\%). Vaginal and anal penetration was noted in $69 \%$ and $26.8 \%$ respectively and $25.4 \%$ engaged in post-mortem sexual activity. After the offence, most of the perpetrators left the victim's body as is $(66.2 \%)$. Interestingly, 
many perpetrators $(40.8 \%)$ handed themselves to the police following the crime, while only a quarter of the sample $(25.4 \%)$ carried on with their routine activities.

\section{INSERT TABLE 1 ABOUT HERE}

The analysis exploring the relationship and the link between the sexual behaviours and the act of killing in intimate partner homicide revealed that $39.4 \%$ of the sample was assigned to the direct profile whereas $54.9 \%$ of the sample was assigned to the indirect profile. Four cases $(5.6 \%)$ could not be assigned due to insufficient evidence allowing for correct classification. Within the direct profile, $64.3 \%$ of killing acts were deemed sexually gratifying while in $35.7 \%$ of cases killing enabled the perpetrator to carry out sexual acts with the victim's body. Within the indirect profile, there were no cases were the killing took place to eliminate a witness to the sexual attack. In $46.2 \%$ of cases, the victim was killed while defending herself and trying to escape the sexual attack. Surprisingly, in 53.8\% of cases sexual violence did not take place but rather the killing occurred in a sexual context (See Table 2 for details).

\section{INSERT TABLE 2 ABOUT HERE}

Vignettes of cases representing the different classification profiles and situations for sexually motivated IPH are presented in Table 3. Vignettes focus on the sexual component within each profile scenario. 


\section{Discussion}

Little is known about components of the crime events of intimate partner homicides and even less about sexual homicides perpetrated by intimate partners. The current study represents an initial attempt to examine sexual homicide perpetrated by intimate partners. As such, it aimed to examine crime scene and Modus Operandi behaviours of intimate partner killings in the context of sexual homicide. Variables for the study were chosen on the basis of previous research examining intimate partner and sexual homicide. Descriptive analyses showed that the most prevalent aggravating circumstances in the lead up to the killing included conflict with the victim before the offence and alcohol/drug use by the perpetrator around the time of the killing. Some evidence of stalking or harassment prior to the killing was present. It was noted in slightly less than a quarter of cases (18.3\%). The majority of homicides took place at home. During the criminal event, more than half of the perpetrators in the sample demonstrated their power, control and superiority. Degrading and humiliating behaviours were less common and appeared in less than a quarter of cases. Interestingly, many perpetrators $(40.8 \%)$ turned themselves into the police following the crime, while only a quarter of the sample carried on with their routine activities.

Overall, these results closely resemble findings obtained by other studies examining intimate partner homicides. For example, Miethe and Regoeczi (2004) noted that many partner killings are impulsive and occur during an argument. Home was the most frequent environment in which the homicide takes place (Miethe \& Regoeczi, 2016; Pettler, 2015) and many perpetrators struggled with substance abuse problems at the time of committing the homicide (Matias et al, 2020; Spencer \& Stith, 2020). Desire to control was one of the primary drivers behind male perpetrator intimate killings (Matias et al, 2020; Spencer \& Stith, 2020) and this is concordant with the findings of the current study. As noted by Geberth (2008) with a certain type of abusive personality, under certain situational settings 
such as intoxication, 'an enraged lover or spouse who is acting under extreme emotional circumstances is capable of anything" (p.452).

Research suggests that stalking by current or former intimate partners may be more prevalent in intimate homicides than in non-fatal intimate violence (Campbell et al., 2007). Most research examining stalker-victim relationship found that ex-intimates are the largest subgroup of stalkers (Sheridan \& Davies, 2001; Tjaden \& Thoennes, 1998). White et al., (2020) noted that ex-intimate stalkers presented with considerably more stalking behaviours, which, in comparison to acquaintances or strangers, were more severe and included thirdparty contact, criminal damage, physical and sexual assault. Unfortunately, stalking has rarely been examined in intimate homicide studies therefore the extent of the association has not been well established (Campbell et al., 2007). The results of the current study show that stalking was prevalent in approximately one quarter of the sample, but these are the cases where sufficient evidence existed to include stalking details in the prosecution files. It is possible that many stalking behaviours were undetected or as noted by Miller (2012) left on file and not pursued by the prosecution. What is specifically challenging in the context of intimate partners is that many behaviours could be classified as 'normal' courtship behaviours following a relationship breakdown (Spitzberg \& Cupach, 2014).

In contrast with previous research on intimate killings indicating that guns increased the risk of homicide (USA; Campbell et al., 2003) or that victims died from a sharp instrument (Europe; Liem \& Koenraadt, 2018; Office for National Statistics, 2019; ), our results indicate that the most frequent method of killing was by strangulation (54.9\%). These results are in fact more concordant with sexual homicide research. Carter et al. (2017) for instance compared sexual killings to non-sexual killings and found that $52.3 \%$ of sexual homicide perpetrators were killed by strangulation. Given that nonfatal strangulation is an important risk factor for IPH (Spencer \& Stith, 2020), these results make sense as the context 
is one of close personal contact that the victim and the perpetrator find themselves in during many sexual IPH scenarios. Further research is required to fully understand the use of weapons in intimate partner sexual homicide. To our knowledge, sexual behaviours in intimate partner killings have not been explored previously. The current study noted that almost $70 \%$ of the sample engaged in vaginal penetration while approximately one quarter of the sample engaged in anal penetration and another quarter engaged in post-mortem sexual activity. When the cases were further assigned as either direct or indirect according to the new classification of sexually motivated killings (Stefanska et al., 2017; Stefanska et al., 2020), the results showed that $39.4 \%$ of the sample belonged to the direct profile meaning that the underlying drive of the act of killing was closely related to the sexual element of the crime and that within a timeline, the sexual element must have occurred either around the time of killing or after the murder (Stefanska et al., 2020). Within the direct profile, $64.3 \%$ of killing acts were deemed sexually gratifying and interestingly in approximately $1 / 3$ of cases the killing occurred during sado-masochistic practices, described by the perpetrator as 'a game that went wrong'. When Bows and Herring (2020) investigated the trial outcomes for such defence in cases involving a female victim, they reported that $62 \%$ of cases resulted in a murder conviction, $28 \%$ a manslaughter conviction, while the remaining cases resulted in either no charges or a not guilty verdict. Our analysis indicates that the guilty verdict mainly relied on photographic or video evidence showing that the victim was in fact not consenting, that she was actively trying to escape the activity, or in fact that the perpetrator continued his sexual activity knowing the victim was non-responsive (either unconscious, dying or dead). Such evidence had to of course exist. Bows and Herring (2020) argue that the central issue is not consent but the lack of mens rea which may result in reducing a murder charge to one of manslaughter or even a not guilty verdict. However, in the case of homicide and sexual activity the case becomes complex for the jury. Rough sex/SM defence used in homicide 
cases has led to campaign calls in England and Wales to reform the law aiming for the defence to be outlawed in the Domestic Abuse Bill under consultation in 2020.

Finally, the results of the current study also showed that $54.9 \%$ of the sample was assigned to the indirect profile meaning that the underlying drive of the act of killing was not related to the sexual element of the crime and in fact it was purely instrumental. Within a timeline, the sexual element must have occurred before the act of killing. (Stefanska et al., 2020). Surprisingly however, in $53.8 \%$ of cases sexual violence did not take place but rather the killing occurred in a sexual context. Cases where the sexual encounter was, in fact, consensual were previously described by Stefanska et al. (2017) who noted that despite the fact that there was no sexual violence within the crime script, cases were categorised as sexual homicide because of forensic evidence. Within the current sample two main themes emerged; either the argument erupted following sex or the perpetrator could not achieve erection and this initiated (usually in light of a comment from the victim) the violent attack. This raises the possibility of over-inclusion of some of the homicides and it appears that clinicians should be especially vigilant when homicide occurred in the context of an intimate relationship.

Geberth (2018) believed that from an investigative standpoint, interpersonal sexrelated homicides include elements of rage, hatred, jealousy or revenge. As such, the psychological underpinnings involve violent thought processes of "If I can't have you, then nobody will have you" (Geberth, 2018, p. 451). Our results are concordant as in-depth analysis of each case scenario revealed that perpetrators did in fact provide such explanation for their actions. This was particularly notable in indirect cases where the victim was killed trying to escape a sexual assault (46.2\% cases in the indirect profile). At the time of the offence, the perpetrator is usually influenced by extreme anger and a verbal disagreement might have erupted just before the attack. As a consequence, the sexual attack was viewed by 
the perpetrator as a form of 'punishment'. Moreover, a similar trend was noted in the direct profile where the killing enabled the perpetrator to carry out sexual acts with the victim's (35.7\% cases in the direct profile). Here however, the sexual act was often described by the perpetrator as the 'act of last possession' (i.e. we were together intimately for the last time) and in some cases it was romanticised.

\section{Limitations}

The data for the current study was collected as part of forensic assessment and was coded from existing files. While the files incorporated complete official documentation of data gathered for Parole Board purposes (e.g. pre-trial information, trial evidence as well as prison clinical files), they varied in content for each homicide case. Some discrepancies in content between the reports were also noted. In the event of discrepancy between the trial or the police information and reports written post-sentence (with information often resting on the perpetrators' disclosures), the study used the former statements. Further, of note is the fact that reports were written by various professionals whose focus would differ depending on their role in the case, although this would be the case in any forensic practice. Implications

Policy: Data on the extent of homicide cases using rough sex/sadomasochism (SM) defence is limited. Bows and Herring (2020) note that a homicide during a sexual encounter has two possible defences. First relates to a lack of the actus reus where it is argued that the act that caused the killing was lawful because it was consented; in the author's view an unlikely defence. Second relates to a lack of mens rea where conduct was committed for the purposes of sexual pleasure and therefore it was sexual, rather than violent. Killing is argued to be accidental. In the case of intimate partner sexual homicide however, the picture is more complex because the accounts of what had happened are often neutralised by the defence team despite bearing all the hallmarks of coercive control linked to domestic abuse. In fact, 
data from our study shows that a murder verdict was mostly given upon photographic or video evidence contrasting the defendant's argument that the victim was enjoying the practices.

Practice: Two issues at the opposite spectrum emerged. On the one hand, the data suggests that in the case of sexual IPH, it is harder to decipher the role of the sexual element because of pre-existing sexual relations between the victim and the perpetrator (and the aforementioned neutralizing account of violence reconstructed as a game). However, it appears that the direct/indirect typology (Stefanska et al., 2017) remains a useful guide although at a treatment stage, we suggest that practitioners explore for the possible domestic violence indicators. On the other hand, in cases of indirect sexual homicide, it appears that sexual violence did not occur because the sexual encounter was, in fact, consensual. Such cases would still be identified as sexual homicide because they occurred in a sexual context and physical evidence met one of the Ressler et al. (1988) criteria. Thus, data suggests that when dealing with sexual IPH, practitioners should always determine the context in which the offence has occurred as this is crucial for treatment purposes (Carter \& Perkins, 2018).

Research: Sexual homicide is understood to represent a hybrid offence combining two different offences, a sexual assault and a homicide. We (the authors) believe that understanding that hybrid should be the primary focus of psychological investigation. The current study however suggests that in the case of sexual IPH there is a possibility that three offences are involved: a sexual assault, a homicide and domestic violence. Although research indicates that previous nonlethal strangulation, death threats, domestic violence are risk factors of IPH, we do not know what role they play in sexual IPH. Further research examining intimate partner sexual homicide is therefore warranted. 


\section{References}

Aldarondo, E., \& Mederos, F. (2002). Men who batter: Intervention and prevention strategies in a diverse society. Civil Research Institute.

Beauregard, E. \& DeLisi, M. (2018a). Stepping stones to sexual murder: the role of developmental factors in the etiology of sexual homicide, $\underline{\text { Journal of Criminal }}$ Psychology, 8(3), 199-214. https://doi.org/10.1108/JCP-02-2018-0010

Beauregard, E., \& DeLisi M. (2018b). Unraveling the personality profile of the sexual murderer. Journal of Interpersonal Violence, 36(7-8), 3536-3556. doi: $10.1177 / 0886260518777012$

Beauregard, E., \& Martineau, M. (2016). The sexual murderer: Offender behaviour and implications for practice. Abingdon, UK: Routledge.

Beauregard, E., \& Proulx, J. (2002). Profiles in the offending process of nonserial sexual murderers. International Journal of Offender Therapy and Comparative Criminology, 46(4), 386-399. doi:10.1177/0306624X02464002

Beauregard, E., Proulx, J., \& St-Yves, M. (2007). Angry or sadistic: Two types of sexual murderers. In J. Proulx, E. Beauregard, M. Cusson, \& A. Nicole (Eds.), Sexual murderers: A comparative analysis and new perspectives (pp. 123-141). Chichester, UK: John Wiley \& Sons.

Beech, A., Fisher, D., \& Ward, T. (2005). Sexual murderers' implicit theories. Journal of Interpersonal Violence, 20(11), 1366-1389. doi:10.1177/0886260505278712

Block, C. R., \& Block, R. (20120. Margo Wilson's contributions to the Chicago homicide dataset: Sexual rivalry and sexual jealousy. Homicide Studies, 16(4), 404-427. https://doi.org/10.1177/1088767912461142 
Block, C. R., Devitt, C. O., Fonda, D., Fugate, M., Marting, C., McFarlane, J., et al. (2000). The Chicago Women's Health Study: Risk of serious injury or death in intimate violence: A collaborative research project. Washington, DC: U.S. Department of Justice, National Institute of Justice.

Bows, H., \& Herring, J. (2020). Getting away with murder? A review of the 'rough sex defence'. The Journal of Criminal Law. Advance online publication. https://doi.org/10.1177/0022018320936777

Campbell, J. C., Glass, N., Sharps, P. W., Laughon, K., \& Bloom, T. (2007). Intimate partner homicide: Review and implications of research and policy. Trauma, Violence, \& Abuse, 8, 246-269. doi:10.1177/1524838007303505

Campbell, J. C., Webster D., Koziol-McLain, J., Block C., Campbell, D., Curry, M. A., et al. (2003). Risk factors for femicide in abusive relationships: Results from a multisite case control study. American Journal of Public Health, 93(7), 1089-1097.

Carter, A.J., Hollin, C.R., Stefanska, E.B., Higgs, T., \& Bloomfield, S. (2017). The use of crime scene and demographic information in the identification of non-serial sexual homicide. International Journal of Offender Therapy and Comparative Criminology, 61(14), 1554-1569. https://doi:10.1177/0306624X16630313

Carter \& Perkins (2018) The assessment of perpetrators of sexual homicide for the purposes of risk reduction in secure psychiatric hospital and prison settings. In J. Proulx, A. J. Carter, É. Beauregard, A. Mokros, R. Darjee, \& J. James (Eds.), Routledge international handbook of sexual homicide studies (pp. 356-369). Abingdon, UK: $\underline{\text { Routledge. }}$

Chan, H. C. O., \& Beauregard, E. (2016). Choice of weapon or weapon of choice? Examining the interactions between victim characteristics in single-victim male 
sexual homicide offenders. Journal of Investigative Psychology and Offender Profiling, 13, 70-88. doi:10.1002/jip.1432

Chan, H. C., Li, F., Liu, S., \& Lu, X. (2019). The primary motivation of sexual homicide offenders in China: Was it for sex, power and control, anger, or money? Criminal Behaviour and Mental Health, 29(3), 168-178.

Chan, H. C. O., Heide K. M., \& Beauregard, E. (2019). Male and Female Single-Victim Sexual Homicide Offenders: Distinguishing the Types of Weapons Used in Killing Their Victims. Sexual Abuse: Journal of Research and Treatment, 31(2), 127-150. https://doi.org/10.1177/1079063217724765

Chéné, S., \& Cusson, M. (2007). Sexual murderers and sexual aggressors: Intention and situation In J. Proulx, E. Beauregard, M. Cusson, \& A. Nicole (Eds.), Sexual murderers: A comparative analysis and new perspectives (pp. 70-86). Chichester, UK: John Wiley \& Sons Ltd.

Clarke, J., \& Carter, A. J. (2000). Relapse prevention with sexual murderers. In D. R. Laws, S. M. Hudson, \& T. Ward (Eds.), Remaking relapse prevention with sex offenders: A sourcebook (pp. 389-401). London: Sage Publications.

Cohen, L. E., \& Felson, M. (1979). Social change and crime rate trends: A routine activity approach. American Sociological Review, 44, 588-608. https://doi: $\underline{10.2307 / 2094589}$

Cooper, Alexia., \& Smith. E. (2011). Homicide Trends in the United States, 1980-2008. Washington, D.C.: U.S. Department of Justice, Bureau of Justice Statistics.

Cunha, O., Gonçalves, R. A. (2016). Severe and less severe intimate partner violence: From characterization to prediction. Violence and Victims, 312(2), 1-16. https://doi:10.1891/0886-6708.VV-D-14-00033 
Dobash, R. E., Dobash, R. P., Cavanagh, K., \& Lewis, R. (2004). Not an ordinary killerJust an ordinary guy. When men murder an intimate woman partner. Violence Against Women, 10, 577-605.

Dutton, D. G. (1985). An ecologically nested theory of male violence toward intimates. International Journal of Women's Studies, 8, 404-413.

Dutton, D. G. (2006). Rethinking domestic violence. Vancouver, BC: University of British Columbia Press.

Dutton, D. G. \& Kropp, P. R. (2000). A review of domestic violence risk instruments. Trauma, Violence \& Abuse, 1, 171-181. https://doi: 10.1177/1524838000001002004

Fox, J. A., \& Zawitz, M. W. (2004). Homicide trends in the United States: 2002 update. Crime brief. Office of Justice Programs, Bureau of Justice Statistics, NCJ 204885.

Garcia, L., Soria, C., \& Hurwitz, E. L. (2007). Homicides and intimate partner violence: A literature review. Trauma, Violence, \& Abuse, 8(4), 370-383. https://doi.org/10.1177/1524838007307294

Geberth, V. J. (2018). Sex-related homicide investigations. In J. Proulx, A. J. Carter, É. Beauregard, A. Mokros, R. Darjee, \& J. James (Eds.), Routledge international handbook of sexual homicide studies (pp. 448-470). Abingdon, UK: Routledge.

Glass, N., Laughon, K., Campbell, J. C., Block, R. B., Hanson, G., \& Sharps, P. S. (2008). Strangulation is an important risk factor for attempted and completed femicides. Journal of Emergency Medicine, 35(3), 329-335.

\section{https://doi.org/10.1016/j.jemermed.2007.02.065}

Goussinsky, R. Dalit Yassour-Borochowitz,D. (2012). I killed her, but I never laid a finger on her - A phenomenological difference between wife-killing and wife-battering, Aggression and Violent Behavior, 17(6), 553-564. https://doi.org/10.1016/j.avb.2012.07.009. 
Greenall, P. V., \& Richardson, C. (2015). Adult male-on-female stranger sexual homicide: A descriptive (baseline) study from Great Britain. Homicide Studies, 19, 237-256. doi:10.1177/1088767914530555

Holtzworth-Munroe. A. \& Stuart, G. L. (1994). Typologies of male batterers: Three subtypes and the difference among them. Psychological Bulletin, 116, 476-497.

Home Office (2013). Circular: New government domestic violence and abuse definition. Retrieved from https://www.gov.uk/government/publications/new-governmentdomestic-violence-and-abuse-definition

Johnson, M.P. (1995). Patriarchal terrorism and common couple violence: Two forms of violence against women. Journal of Marriage and the Family, 57, 283-294. https://doi.org/10.2307/353683

Johnson, M. P. (2011). Gender types of intimate partner violence: A response to an antifeminist literature review. Aggression and Violent Behavior, 16, 289-296. https://doi.org/10.1016/j.avb.2011.04.006

Langevin, R., Ben-Aron, M. H., Wright, P., Marchese, V., \& Handy, L. (1988). The sex killer. Annals of Sex Research, 1(2), 263-301. doi:10.1007/BF00852801

Kocsis, R. N. (1999). Criminal profiling of crime scene behaviours in Australian sexual murders. Australian Police Journal, 53(2), 98-101.

Liem, M., \& Koenraadt, F. (2018). Familicide: a comparison with spousal and child homicide by mentally disordered perpetrators. Criminal Behaviour and Mental Health, 18, 306318. https://doi:10.1002/cbm.710

Matias, A., Gonçalves, M., Soeiro, C., Matos, M., (2020). Intimate partner homicide: A metaanalysis of risk factors, Aggression and Violent Behavior, 50, https://doi.org/10.1016/j.avb.2019.101358. 
Mieczkowski, T., \& Beauregard, E. (2012). Interactions between disinhibitors in sexual crimes: additive or counteracting effects? Journal of Crime and Justice, 35(3), 395411. doi:10.1080/0735648X.2012.666408

Miller, L. (2012). Stalking: Patterns, motives, and intervention strategies. Aggression and Violent Behavior, 17(6), 495-506. https://doi.org/10.1016/j.avb.2012.07.001

Milsom, J., Beech, A. R., \& Webster, S. D. (2003). Emotional loneliness in sexual murderers: A qualitative analysis. Sexual Abuse: A Journal of Research and Treatment, 15(4), 285-296. doi:10.1023/A:1025095927047

McFarlane J., Campbell, J.C., \& Watson, K. (2002). Intimate partner stalking and femicide: urgent implications for women's safety. Behavioral Sciences and the Law, 20, 51-68. https://doi:10.1002/bsl.477 12030246

Nicole, A., \& Proulx, J. (2007). Sexual murderers and sexual aggressors: Developmental paths and criminal history. In J. Proulx, É. Beauregard, M. Cusson, \& A. Nicole (Eds.), Sexual murderers: A comparative analysis and new perspectives. (pp. 29-50). Chichester, UK: John Wiley \& Sons Ltd.

Office for National Statistics (2019).

https://www.ons.gov.uk/peoplepopulationandcommunity/crimeandjustice/bulletins/do $\underline{\text { mesticabuseinenglandandwalesoverview/november2019 }}$

O’Leary, K. D., Smith Slep, A. M., \& O’Leary, S. G. (2007). Multivariate models of men's and womens' partner aggression. Journal of Consulting and Clinical Psychology, 75, 752-764. doi:10.1037/0022-006X.75.5.752

O’Leary, K. D., Tintle, N. \& Bromet, E. (2014). Risk factors for physical violence against partners in the U.S. Psychology of Violence, 4, 65-77. doi:10.1037/a0034537 
Pettler, L.G. (2015). Crime Scene Staging Dynamics in Homicide Cases. Taylor \& Francis Group.

Proulx, J., Blais, E., \& Beauregard, E. (2007). Sadistic sexual offenders. In J. Proulx, E. Beauregard, M. Cusson, \& A. Nicole (Eds.), Sexual murderers: A comparative analysis and new perspectives (pp. 107-122). Hoboken, NJ: Wiley.

Proulx, J., \& Sauvêtre, N. (2007). Sexual murderers and sexual aggressors: Psychopathological considerations. In J. Proulx, E. Beauregard, M. Cusson, \& A. Nicole (Eds.), Sexual murderers: A comparative analysis and new perspectives. (pp. 51-69). Chichester, UK: John Wiley \& Sons Ltd.

Reckdenwald, A., \& Parker K.F. (2012). Understanding the change in male and female intimate partner homicide over time: A policy-and theory-relevant investigation. Feminist Criminology. 7(3):167-195. doi:10.1177/1557085111428445

Rennison, C.M., \& Welchans, S. (2000). Intimate partner violence. U.S. Department of Justice; Washington, DC.

Sharps, P. W., Campbell, J. C., Campbell, D. W., Gary, F. A., \& Webster, D. W. (2001). The role of alcohol use in intimate partner femicide. American Journal on Addictions, 10, 122-135. doi: 10.1080/105504901750227787

Sheridan, L., Gillett, R., \& Davies, G. (2000). 'Stalking'-Seeking the victim's perspective. Psychology, Crime and Law, 6(4), 267-280. doi: 10.1080/10683160008409807

Spencer, C. M, \& Stith, S. M. (2020). Risk factors for male perpetration and female victimization of intimate partner homicide: A meta-analysis. Trauma, Violence \& Abuse, 21(3), 527-540. https://doi:10.1177/1524838018781101

Spitzberg, B. H., \& Cupach, W. R. (2007). The state of the art of stalking: Taking stock of the emerging literature. Aggression and Violent Behaviour, 12(1), 64-86. 
Stefanska, E. B., Higgs, T., Carter, A. J., \& Beech, A. R. (2017). When is a murder a sexual murder? Understanding the sexual element in the classification of sexual killings. Journal of Criminal Justice, 50, 53-61. doi:10.1016/j.jcrim- jus.2017.03.004

Stefanska, E.B., Longpré, N., Bloomfield, S, Perkins, D., \& Carter, A.J. (2020). Untangling sexual homicide: A proposal for a new classification of sexually motivated killings. Journal of Criminal Justice. Advance Online Publication.

\section{https://doi.org/10.1016/j.jcrimjus.2020.101729}

Stith, S. M., Smith, D. B., Penn, C. E., Ward, D. B., \& Tritt, D. (2004). Intimate partner physical abuse perpetration and victimization risk factors: A meta-analytic review. Aggression and Violent Behavior, 10, 65-98. doi: 10.1016/j.avb.2003.09.001

Tjaden, P., \& Thoennes, N. (1998). Stalking in America: Findings from the national violence against women survey. Washington, DC: National Institute of Justice and Centers for Disease Control and Prevention. 1-19.

Weinsheimer, R. L., Schermer, C. R., Malcoe, L. H., Balduf, L. M., \& Bloomfield, L. A. (2005). Severe intimate partner violence and alcohol use among female trauma patients. Journal of Trauma, Injury, Infection, and Critical Care, 58(1), 22-29.

White. E., \& Longpre., N., \& Stefanska. E. (2020). Stalking Behaviors Presented by ExIntimate Stalkers: A Victim's Perspective. Journal of Interpersonal Violence. Advance Online Publication. https://doi.org/10.1177/0886260520934429

World Health Organization (2017). Violence against Women. https://www.who.int/news$\underline{\text { room/fact-sheets/detail/violence-against-women }}$ 